\title{
Erythrina velutina WILLD. (LEGUMINOSAE-PAPILIONOIDEAE) OCORRENTE EM CAATINGA E BREJO DE ALTITUDE DE PERNAMBUCO: BIOMETRIA, EMBEBIÇÃO E GERMINAÇÃO ${ }^{1}$
}

\author{
Valter Tavares da Silva Junior², Jéssica Maria Góis Miranda de Lima³, Cynthia Waleria de Melo Silva \\ Rodrigues ${ }^{4}$ e Dilosa Carvalho de Alencar Barbosa ${ }^{5}$
}

\begin{abstract}
RESUMO - O objetivo deste trabalho foi comparar a biometria de frutos e sementes, a embebição e germinação de duas populações de Erythrina velutina coletadas na região semiárida do Estado de Pernambuco, nas áreas de caatinga (Alagoinha) e no brejo de altitude (Poção). Os frutos e as sementes foram avaliados quanto ao comprimento, largura, espessura $(\mathrm{cm})$ e peso $(\mathrm{g})$. Com relação às sementes, foram analisados o número por fruto, o volume $\left(\mathrm{cm}^{3}\right)$ e a embebição, bem como a germinação com e sem escarificação mecânica, na presença constante de luz a $25{ }^{\circ} \mathrm{C}$. Os frutos e sementes do brejo apresentaram os valores assim discriminados: 9,65 x 1,57 x 1,22 cm, $1,43 \mathrm{~g}$ e 1,34 x 0,92 x 0,78 cm, 0,46 g; e na caatinga: 6,85 x 1,19 x 1,03 cm, 0,21 g e 1,06 x 0,63 x 0,63 cm e 0,26 g. O número de sementes e o volume no brejo e caatinga foram de 2,33 e $1,38 \mathrm{~cm}^{3}$ e 1,40 e $0,23 \mathrm{~cm}^{3}$, respectivamente. Todas as sementes escarificadas apresentaram maiores valores de embebição e porcentagem de germinação. Quanto à velocidade de germinação, foi maior na caatinga. Esses resultados indicam que as condições ambientais do brejo de altitude favorecem o desenvolvimento dos frutos e das sementes.
\end{abstract}

Palavras-chave: Frutos, Sementes, Volume Peso e Escarificação.

\section{Erythrina velutina WILLD. (LEGUMINOSAE-PAPILIONOIDEAE) OCCURRING IN CAATINGA AND BREJO DE ALTITUDE OF PERNAMBUCO: BIOMETRICS, IMBIBITION AND GERMINATION.}

\begin{abstract}
The objective of this study was to compare the biometry of fruits and seeds, the imbibition and germination of two populations of Erythrina velutina collected in semi-arid region of Pernambuco state, in areas of caatinga (Alagoinha) and brejo de altitude (upper land swams) (Poção). The fruits and seeds were evaluated for length, width, thickness $(\mathrm{cm})$ and weight $(\mathrm{g})$. Regarding the seeds, it was analyzed the number per fruit, volume $\left(\mathrm{cm}^{3}\right)$, embebition and germination with and without mechanical scarification at the presence of constant light at $25^{\circ} \mathrm{C}$. The fruits and seeds from the swamp presented the following values: $9.65 \times 1.57 \times 1.22 \mathrm{~cm}, 1.43 \mathrm{~g}$ and $1.34 \times 0.92 \times 0.78 \mathrm{~cm}, 0.46 \mathrm{~g}$; and the ones from presented the following values: $6.85 \times 1.19 \times 1.03 \mathrm{~cm} ; 0.21 \mathrm{~g}$ and $1.06 \times 0.63 \times 0.63 \mathrm{~cm}$ and $0.26 \mathrm{~g}$. Number of seeds per fruit and volume in the swamp and Caatinga were 2.33 and $1.38 \mathrm{~cm}^{3}$ and 1.40 and $0.23 \mathrm{~cm}^{3}$, respectively. All scarified seed from both places presented the highest values for embebition and percentage of germination. Germination rate was the highest in seeds from Caatinga. These results indicate that the environmental conditions of the upper land swamp favored the development of the fruits and seeds.
\end{abstract}

Keywords: Fruit, Seed, Volume, Mass and Scarification.

\footnotetext{
${ }^{1}$ Recebido em 20.12.2008 e aceito para publicação em 29.03.2012.

${ }^{2}$ Instituto Federal de Pernambuco - Campus Recife. E-mail:<jrbiologia@hotmail.com>.

${ }^{3}$ Mestre em biologia Vegetal pela Universidade Federal de Pernambuco. E-mail: <jessica.bio@hotmail.com >.

${ }^{4}$ Escola Joaquim Xavier de Brito, EJXB, Brasil. E-mail: <cynthiawaleria@hotmail.com >.

${ }^{5}$ Universidade Federal de Pernambuco, UFPE, Brasil. E-mail: <dilosabarbosa@yahoo.com.br >.
} 


\section{INTRODUÇÃO}

Erythrina velutina é uma árvore de 8-12 m de altura, com flores vermelhas, fruto do tipo folículo, distribuída nas Américas Central e do Sul. É característica de várzea úmida e margens de rios temporários da caatinga na região semiárida nordestina(VASCONCELO SOBRINHO, 1970; SALES et al., 1998).

Na região semiárida de Pernambuco, o bioma Caatinga apresenta maior extensão, com altitudes que variam de 400 a $700 \mathrm{~m}$, e circunda os brejos de altitude ou matas serranas, os quais constituem disjunções da floresta tropical perenifólia, com altitudes de 600 a $1.100 \mathrm{~m}$, ocorrendo nos topos e encostas superiores a barlavento das serras situadas no Planalto da Borborema (ANDRADE LIMA, 1966; RODAL et al., 1998) e apresentando algumas espécies com distribuição amazônica e outras típicas de florestas serranas do Sul e Sudeste do Brasil (TABARELLI; SANTOS, 2004). Ferraz et al. (1998) comentaram que essas formações, embora próximas, apresentam características climáticas, edáficas, topográficas, florísticas e fisionômicas distintas.

Vários processos ecológicos são influenciados pelo tamanho dos frutos e das sementes, como germinação (COUVILLON, 2002) e dispersão (LORD; MARSHALL, 2001). Sementes grandes geralmente possuem melhor qualidade fisiológica, o que pode ser vantajoso em condições de sombreamento (WHITE; GONZÁLES, 1990), sendo relacionada com estágios sucessionais tardios (SOUZA; VÁLIO, 2003). Entretanto, as sementes pequenas apresentam facilidades para a dispersão pelo vento, além de possuírem a habilidade de germinar rápido em ambientes desfavoráveis (BARBOSA, 2003), podendo, ainda, formar banco de sementes no solo (THOMPSON et al., 2001) e ser consideradas como sementes de plantas pioneiras (SOUZA; VÁLIO, 2003). Tabarelli et al. (2003) observaram que na região semiárida nordestina os frutos grandes e carnosos diminuem à medida que há decréscimo no gradiente de precipitação. Verificaram ainda que, embora não houvesse correlação positiva entre o tamanho do fruto e a pluviosidade nos locais analisados, a porcentagem de espécies de frutos pequenos diminuiu de $20 \%$ para $13,2 \%$, e a de frutos grandes aumentou de $6,6 \%$ para $14,5 \%$, em pluviosidades médias de $400 \mathrm{~mm}$ e $600 \mathrm{~mm}$, respectivamente.

Segundo Bewley e Black (1994), a germinação de uma semente começa com a absorção de água (embebição). O primeiro estágio de embebição da água pela semente ocorre através de rápida hidratação. Diante disso, conclui-se que o processo de embebição é puramente físico, tendo em vista que sementes mortas ou, mesmo, dormentes (sem impedimento físico) apresentam o mesmo padrão de embebição inicial de água que as sementes vivas (BORGES; RENA, 1993). A velocidade de embebição da água pela semente pode variar diante de alguns fatores, como: espécie, indivíduo parental, permeabilidade do tegumento, disponibilidade de água do substrato, temperatura, pressão hidrostática, área de contato semente/água, forças intermoleculares, composição química e condições fisiológicas (MAYER; POLJAKOFF-MAYBER, 1979; POPINIGIS, 1985).

A germinação é um momento mais crítico para o estabelecimento das plantas em seu habitat, sendo muitos os fatores (umidade, temperatura, oxigênio, luz e tegumento duro, entre outros) fundamentais para que o processo se realize normalmente (LARCHER, 2000). A dormência é o período em que a semente não germina, mesmo que o meio ofereça condições favoráveis à germinação. Há várias situações que podem gerar esse período: impermeabilidade do tegumento, imaturidade do embrião e a presença de inibidores químicos na semente e, ou, no fruto (WACHOWICZ e CARVALHO, 2002; FERREIRA; BORGHETTI, 2004). A dormência nas leguminosas é geralmente imposta pela presença de um tegumento duro na semente e a germinação, por sua vez, depende de alterações no tegumento (VILLALOBOS; PELÁEZ, 2001).

O objetivo deste trabalho foi estudar a biometria dos frutos e das sementes, a embebição e germinação das sementes de Erythrina velutina Willd., coletadas em duas áreas (caatinga e brejo de altitude) da região semiárida do Estado de Pernambuco.

\section{MATERIAL E MÉTODOS}

Frutos maduros de Erythrina velutina Willd. foram coletados no mês de março de 2003, diretamente das copas das plantas parentais, na época chuvosa, em duas populações, provenientes de duas localidades na região semiárida de Pernambuco. Ambas as propriedades particulares, a primeira no Sítio Riacho, Município de Alagoinha, a 700 m de altitude (8'30'0'” S e 3648'0' $\mathrm{W}$ ), e a segunda no km 12, distante da primeira cerca de $50 \mathrm{~km}$, no Município de Poção, a 950 m (8¹2’0”'S e 3642’0”'W), correspondentes às áreas de caatinga hipoxerófila (transição entre as zonas fitogeográficas de mata úmida e de caatinga, 
em geral mais densa, em cuja área as chuvas se distribuem menos irregularmente e em totais mais elevados que nas hiperxófilas ocorrentes no sertão) e brejo de altitude, respectivamente (JACOMINE et al., 1973; FIAM 1996). Segundo os dados do LAMEP/ITEP (2003), os valores médios da precipitação anual de janeiro de 1993 a dezembro de 2002, em Alagoinha e Poção, foram de 447,2 mm e 676,2 $\mathrm{mm}$, respectivamente. A temperatura média anual foi de $23^{\circ} \mathrm{C}$ em Alagoinha e $20^{\circ} \mathrm{C}$ em Poção, nesses mesmos anos. Os meses de maior pluviosidade foram janeiro a maio em Alagoinha e março a junho em Poção. As menores temperaturas ocorreram entre julho e agosto, em ambos os locais (Figura 1). O resultado da análise de $1 \mathrm{~kg}$ de

Fonte: Lamep/ITEP.

Source: Lamep/ITEP.
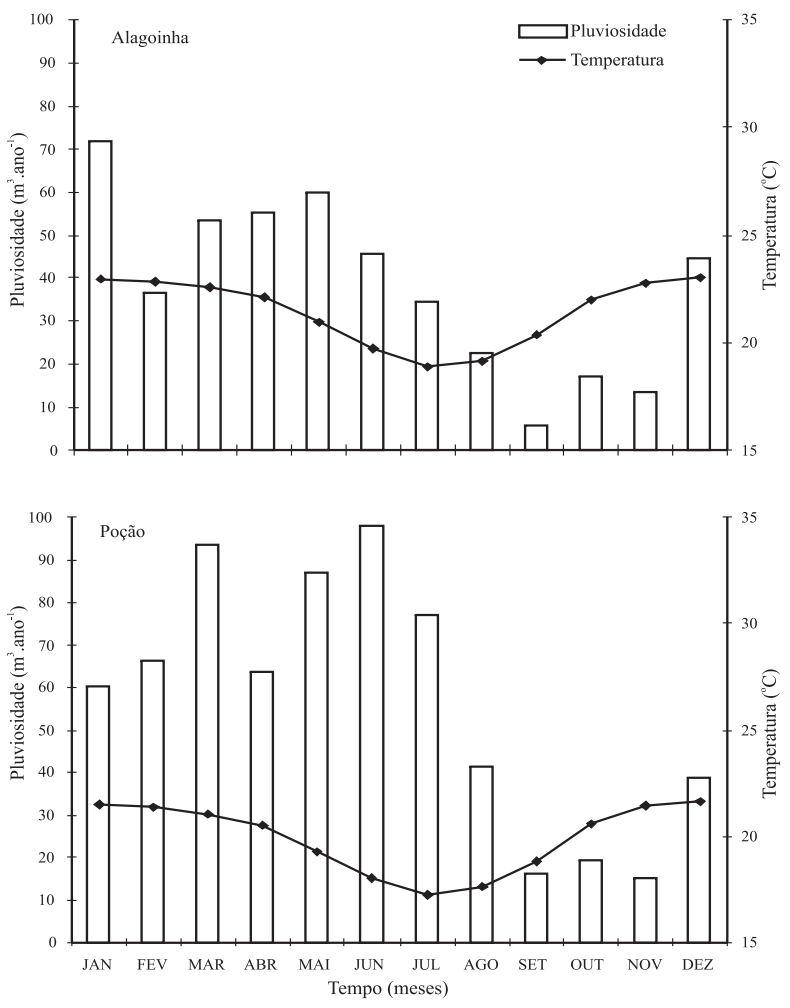

Figura 1 - Médias de pluviosidade e temperatura ocorrentes entre janeiro de 1994 e dezembro de 2003, nos Municípios de Alagoinha (caatinga) e Poção (brejo de altitude), na região semiárida do Estado de Pernambuco.

Figure 1 - Means of temperature and rainfall occurring from January 1994 to December 2003, in the municipalities of Alagoinha (Caatinga) and Poção (upper land swamp) in the semi-arid region of the state of Pernambuco.Source: Lamep/ITEP. solo coletado na profundidade de 5 a $20 \mathrm{~cm}$ na caatinga e no brejo de altitude apresentou diferença quanto aos aspectos físico e químico. O solo da caatinga é do tipo areia franca, enquanto o solo do brejo é francoarenoso (Tabela 1). O solo da caatinga é mais pobre por apresentar menor porcentagem de nutrientes que o do brejo de altitude (Tabela 2). Portanto, são encontradas condições de maiores temperaturas e menores taxas de pluviosidade e riqueza do solo na área de caatinga selecionada em relação à área do brejo de altitude.

Avaliação da biometria - os frutos, após a coleta, foram acondicionados em sacos plásticos etiquetados, onde permaneceram por $24 \mathrm{~h}$ na temperatura ambiente até serem conduzidos ao Laboratório de Fisiologia Vegetal do Departamento de Botânica da Universidade Federal de Pernambuco. A seguir permaneceram por três dias em bandejas de plástico, em casa de vegetação, nas dependências do Departamento de Botânica, com temperatura e umidade relativa média de $28^{\circ} \mathrm{C}$ e $74 \%$, respectivamente. Após esse período, os frutos foram acondicionados em recipientes plásticos com tampas do mesmo material, contendo em seu interior sílica-gel para manutenção da baixa umidade e mantidos em condições de laboratório ( $27^{\circ} \mathrm{C}$ e $80 \%$ U.R.). Em seguida foram medidos os frutos e as sementes, utilizando-se 100 unidades cada: comprimento $(\mathrm{cm})$, largura $(\mathrm{cm})$ e espessura $(\mathrm{cm})$, com o auxílio de um paquímetro; e a massa (g), em balança semianalítica HD-200. O volume das sementes foi calculado usando-se 20 réplicas de cinco sementes cada, imersas em água destilada dentro de uma proveta com capacidade para $1.000 \mathrm{~cm}^{3}$ (CRUZ et al., 2001). O número de sementes por fruto foi determinado pela contagem direta nos frutos. Foram determinadas as massas (g) de 100 frutos e 100 sementes, segundo a Regra de Análise de Sementes (BRASIL, 1992).

Avaliação da embebição - $O$ teste foi realizado em 100 sementes por localidade, sendo 50 intactas e 50 escarificadas mecanicamente com lixa de ferro, todas imersas em $100 \mathrm{~mL}$ de água destilada no interior de um béquer, durante todo o experimento. O peso das sementes embebidas foi mensurado antes da embebição e a cada duas horas, durante 12 horas.

Avaliação da germinação - Foram utilizadas 100 sementes para o teste de germinação por localidade, sendo 100 escarificadas com lixa de ferro e 100 intactas (controle). As sementes foram semeadas em placas 
Tabela 1 - Análise física dos solos coletados a $10 \mathrm{~cm}$ de profundidade em duas áreas (caatinga e brejo de altitude), na região semiárida de Pernambuco.

Table 1 - Physical analysis of soil collected at $10 \mathrm{~cm}$ deep in two areas (Caatinga and upper land swamp) in semi-arid region of Pernambuco.

\begin{tabular}{|c|c|c|c|c|c|c|c|c|c|}
\hline \multirow[t]{2}{*}{ Local } & \multicolumn{4}{|c|}{ Granulometria $\left(\mathrm{g} \cdot \mathrm{kg}^{-1}\right)$} & \multicolumn{2}{|c|}{ Densidade $\left(\mathrm{g} . \mathrm{cm}^{-3}\right)$} & \multirow{2}{*}{$\begin{array}{c}\text { Classificação } \\
\text { Textural }\end{array}$} & \multicolumn{2}{|c|}{ Umidade $\%(\mathrm{~m} / \mathrm{m})$} \\
\hline & Areia grossa & Areia fina & Silte & Argila & Aparente & Real & & $1,5 \mathrm{MPa}$ & $0,01 \mathrm{MPa}$ \\
\hline Caatinga & 612 & 229 & 119 & 40 & 1,61 & 2.64 & Areia franca & 2,60 & 6,90 \\
\hline Brejo & 560 & 180 & 100 & 160 & 1,40 & 2.63 & Francoarenoso & 5,20 & 11,16 \\
\hline
\end{tabular}

Análises feitas pelo Laboratório de Solos, IPA.

Tabela 2 - Análise química dos solos coletados a $10 \mathrm{~cm}$ de profundidade em duas áreas (caatinga e brejo de altitude), na região semiárida de Pernambuco.

Table 2 - Chemical analysis of soil collected at $10 \mathrm{~cm}$ deep in two areas (Caatinga and upper land swamp) in semi-arid region of Pernambuco.

\begin{tabular}{|c|c|c|c|c|c|c|c|c|}
\hline & \multirow{2}{*}{$\begin{array}{c}\text { Saturação } \\
(\%)\end{array}$} & \multirow{2}{*}{$\begin{array}{c}\mathrm{pH} \\
\left(\mathrm{H}_{2} \mathrm{O}\right)\end{array}$} & \multicolumn{4}{|c|}{ Complexo sortivo $\left(\mathrm{cmol}(+) \cdot \mathrm{kg}^{-1}\right)$} & \multirow{2}{*}{$\begin{array}{c}\mathrm{C} \\
\left(\mathrm{g}^{-\mathrm{kg}^{-1}}\right)\end{array}$} & \multirow{2}{*}{$\begin{array}{c}\mathrm{N} \\
\left(\mathrm{g} \cdot \mathrm{kg}^{-1}\right)\end{array}$} \\
\hline & & & $\mathrm{Ca}$ & $\mathrm{Mg}$ & $\mathrm{K}$ & $\mathrm{Na}$ & & \\
\hline Caatinga & 26 & 7,00 & 2,36 & 1,03 & 0,15 & 0,23 & 3,20 & 0,40 \\
\hline Brejo & 30 & 6,72 & 5,10 & 2,95 & 0,35 & 0,35 & 5,70 & 0,90 \\
\hline
\end{tabular}

Análises feitas pelo Laboratório de Solos, IPA.

de Petri de 9 cm de diâmetro com duplo papel-filtro, sendo utilizadas 50 intactas e 50 escarificadas, com 10 sementes por placa e cinco réplicas, envoltas em papel parafilme. As sementes foram embebidas em $10 \mathrm{~mL}$ de água destilada e postas para germinar em câmara de germinação B.O.D. sob luz contínua, na temperatura constante de $25{ }^{\circ} \mathrm{C}$. Acompanhou-se a germinação diariamente, durante 15 dias, tendo como critério a emissão da radícula (LABOURIAU, 1983). Foram calculadas a porcentagem e velocidade média de germinação. Para a análise dos dados de germinação, os valores foram convertidos em arcosseno “\%/100.

Análise estatística - Os dados foram avaliados quanto à sua normalidade através do teste de Kolmogorov-Smirnov. As médias de biometria dos frutos e sementes foram comparadas entre as duas localidades pelo teste de Mann-Whitnay. Para comparar as médias de embebição, aplicou-se a análise de variância simples (ANOVA), seguida do teste de Tukey. A germinação foi analisada pelo teste $t$ de amostras independentes, sendo todos os testes realizados a 5\% de probabilidade, através do programa Biostat 2.0 (AYRES et al., 1998).

\section{RESULTADOS E DISCUSSÃO}

Biometria - Os frutos de Erythrina velutina são deiscentes quando maduros e de coloração marrom, e as sementes, ao serem liberadas, apresentam coloração vermelha, o que favorece a visualização delas em meio aos galhos e troncos das árvores circunvizinhas. A coloração dos diásporos pode influenciar a taxa de visita de animais aos indivíduos frutificados, podendo ser também sinal da existência de alguma reserva, servindo para atração de consumidores dos frutos ou indicativo da qualidade destes (WILLSON et al., 1989).

Na Figura 2 estão apresentados os dados de biometria dos frutos de E. velutina, nos quais foram verificados que o comprimento, largura e espessura dos frutos coletados na área de caatinga variaram de 5,50 a $10,20 \mathrm{~cm}$, de 1,00 a $1,40 \mathrm{~cm}$ e de 0,90 a $1,17 \mathrm{~cm}$, respectivamente. Os frutos coletados na área de brejo de altitude variaram de 5,50 a 13,80 cm no comprimento, de 1,40 a 1,70 cm na largura e de 1,08 a 1,50 cm na espessura. As classes de tamanho de 5,50 a 6,60 cm e 10,30 a 11,40 cm no comprimento, de 0,99 a 1,07 e de 1,17 a $1,25 \mathrm{~cm}$ na largura e de 1,20 cm a 1,60 cm na espessura representaram a maioria dos frutos coletados em áreas de caatinga e brejo de altitude, respectivamente. Os frutos de E. velutina coletados na caatinga exibiram valores médios para comprimento, largura e espessura menores e com diferenças significativas em relação àquelas registrados para o brejo de altitude (Tabela 3).

Revista Árvore, Viçosa-MG, v.36, n.2, p.247-257, 2012 

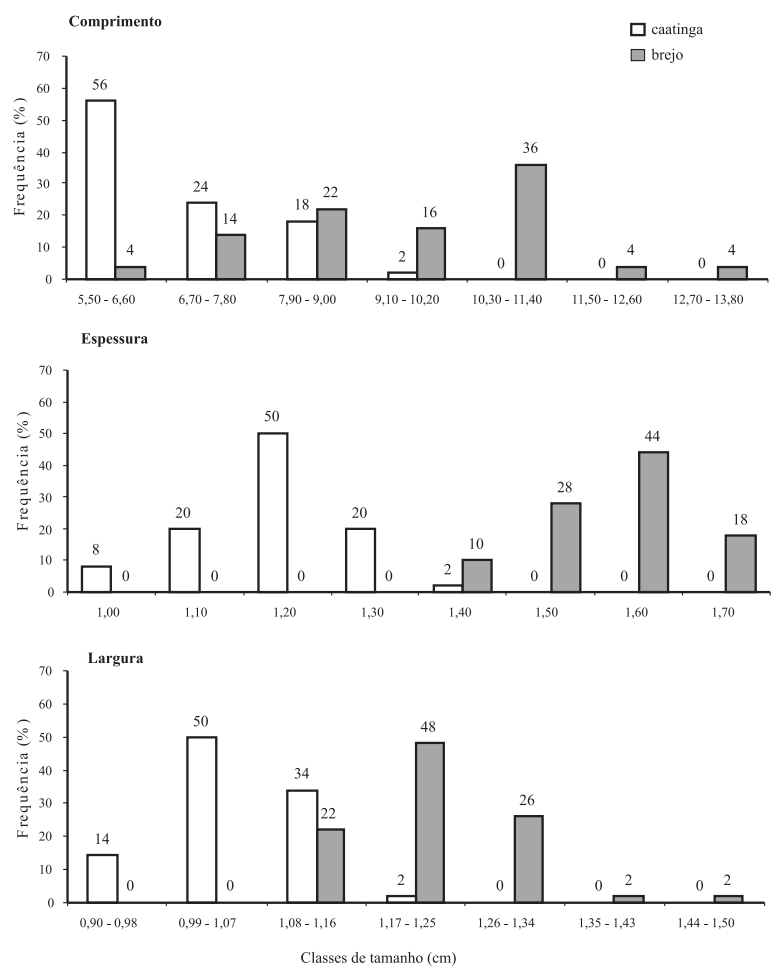

Figura 2 - Comprimento, largura e espessura $(\mathrm{cm})$ de frutos de Erythrina velutina Willd coletados em duas áreas (caatinga e brejo de altitude), na região semiárida de Pernambuco. O número ao lado das barras representa o valor absoluto.

Figure 2 - Length, width and thickness (cm) of fruit in Erythrina velutina Willd collected in two areas (Caatinga and upper land swamp) in semi-arid region of Pernambuco. The number next to the bar represents the absolute value.

O número de sementes por fruto variou de 1 a 3 e de 1 a 4, nos frutos coletados nas áreas de caatinga e brejo de altitude, respectivamente, apresentando, portanto, maior número de sementes nos frutos coletados no brejo de altitude (Tabela 4). Sassaki e Felippe (1999), ao discutirem sobre o número de sementes por fruto, verificaram que menor número de sementes por fruto em Dalbergia miscolobium Benth resultou em maior reserva da semente. Concordando com esse fato, Khan et al. (1999) observaram que as sementes provenientes de frutos com menor número de sementes por fruto em Messua ferrea Linn originaram plântulas mais vigorosas. Ainda segundo Sassaki e Felippe (1999), a quantidade de sementes, bem como a posição no fruto, constitui estratégias diferenciais para o
Tabela 3 - Médias de comprimento, largura e espessura (cm) de frutos e sementes de Erythrina velutina Willd. coletados em duas áreas (caatinga e brejo de altitude), na região semiárida de Pernambuco.

Table 3 - Means of length, width and thickness $(\mathrm{cm})$ of fruits and seeds of Erythrina velutina Willd. collected in two areas (Caatinga and upper land swamp) in semi-arid region of Pernambuco.

\begin{tabular}{lllllll}
\hline & \multicolumn{2}{c}{ Caatinga } & & \multicolumn{2}{c}{ Brejo de altitude } \\
\cline { 2 - 3 } & Média & \pm & d.p. & & Média & \pm d.p. \\
\hline Fruto & & & & & & \\
$\quad$ Comprimento $(\mathrm{cm})$ & $6,85 \mathrm{a}$ & $\pm 0,97$ & & $9,65 \mathrm{~b}$ & $\pm 1,66$ \\
$\quad$ Largura $(\mathrm{cm})$ & $1,19 \mathrm{a}$ & $\pm 0,09$ & & $1,57 \mathrm{~b}$ & $\pm 0,09$ \\
$\quad$ Espessura $(\mathrm{cm})$ & $1,03 \mathrm{a}$ & $\pm 0,06$ & & $1,22 \mathrm{~b}$ & $\pm 0,08$ \\
\hline Semente & & & & & & \\
$\quad$ Comprimento $(\mathrm{cm})$ & $1,06 \mathrm{a}$ & $\pm 0,06$ & & $1,34 \mathrm{~b}$ & $\pm 0,09$ \\
$\quad$ Largura $(\mathrm{cm})$ & $0,63 \mathrm{a}$ & $\pm 0,06$ & & $0,92 \mathrm{~b}$ & $\pm 0,07$ \\
$\quad$ Espessura $(\mathrm{cm})$ & $0,63 \mathrm{a}$ & $\pm 0,05$ & & $0,78 \mathrm{~b}$ & $\pm 0,06$ \\
\hline
\end{tabular}

As letras minúsculas comparam as médias entre as colunas. Letras iguais não diferem significativamente, pelo teste de Mann-Whitney $(\mathrm{P}>0,05)$.

The lowercase letters compare within each column. Lyrics equals do not differ significantly by ANOVA in soaking, and by t test for independent samples in percentage and speed of germination $(P>0.05)$.

Tabela 4 - Embebição (\%), germinação final (\%) e velocidade média de germinação $\left(\mathrm{d}^{-1}\right)$ sob luz contínua e temperatura constante de $25^{\circ} \mathrm{C}$, em sementes de Erythrina velutina Willd. coletadas em duas áreas (caatinga e brejo de altitude), na região semiárida de Pernambuco

Table 4 - Imbibition (\%), final germination (\%) and average speed of germination (d-1) under continuous light and constant temperature of $25^{\circ} \mathrm{C}$ in seeds of Erythrina velutina Willd. collected in two areas (Caatinga and upper land swamp) in the semiarid region of Pernambuco

\begin{tabular}{ccccc}
\hline Semente & Tratamento & $\begin{array}{c}\text { Embebição } \\
(\%)\end{array}$ & $\begin{array}{c}\text { Germinação } \\
(\%)\end{array}$ & $\begin{array}{c}\text { Velocidade } \\
\left(\mathrm{d}^{-1}\right)\end{array}$ \\
\hline Caatinga & Controle & $0,25 \mathrm{c}$ & - & - \\
& Escarificada & $150,25 \mathrm{~b}$ & $95 \mathrm{a}$ & $0,254 \mathrm{a}$ \\
\multirow{2}{*}{ Brejo } & Controle & $0,20 \mathrm{c}$ & - & - \\
& Escarificada & $162,34 \mathrm{a}$ & $100 \mathrm{a}$ & $0,208 \mathrm{~b}$ \\
\hline
\end{tabular}

As letras minúsculas comparam dentro de cada coluna. Letras iguais não diferem significativamente pelo teste ANOVA na embebição e, pelo teste $t$, em amostras independentes na porcentagem e velocidade de germinação $(P>0,05)$. O símbolo - representa ausência de germinação.

The lowercase letters compare within each column. Equal letter do not differ significantly by ANOVA in imbibition, and by the test for independent samples in percentage and germination rate $(P>0.05)$. The symbol - represents absence of germination. 
estabelecimento e dispersão das espécies, uma vez que influenciam na distribuição da massa entre as sementes e na sua capacidade germinativa.

Os frutos coletados no brejo de altitude apresentaram variação para massa de 0,72 a 2,45 g e de 0,40 a 1,45 g para os frutos da caatinga (Figura 3 ). O maior acúmulo de massa nos frutos se incluiu na classe de 0,40 a 0,68 g e de 0,69 a 1,55 g, na caatinga e no brejo de altitude, respectivamente (Figura 3). A massa média dos frutos de E. velutina coletados na caatinga e no brejo de altitude foi de 0,61 e 1,43 g (Tabela 3). Portanto, os frutos da caatinga foram mais leves e apresentaram menor número de sementes que os do brejo de altitude. Esses resultados podem ter sido influenciados pelas condições da caatinga de Alagoinha,
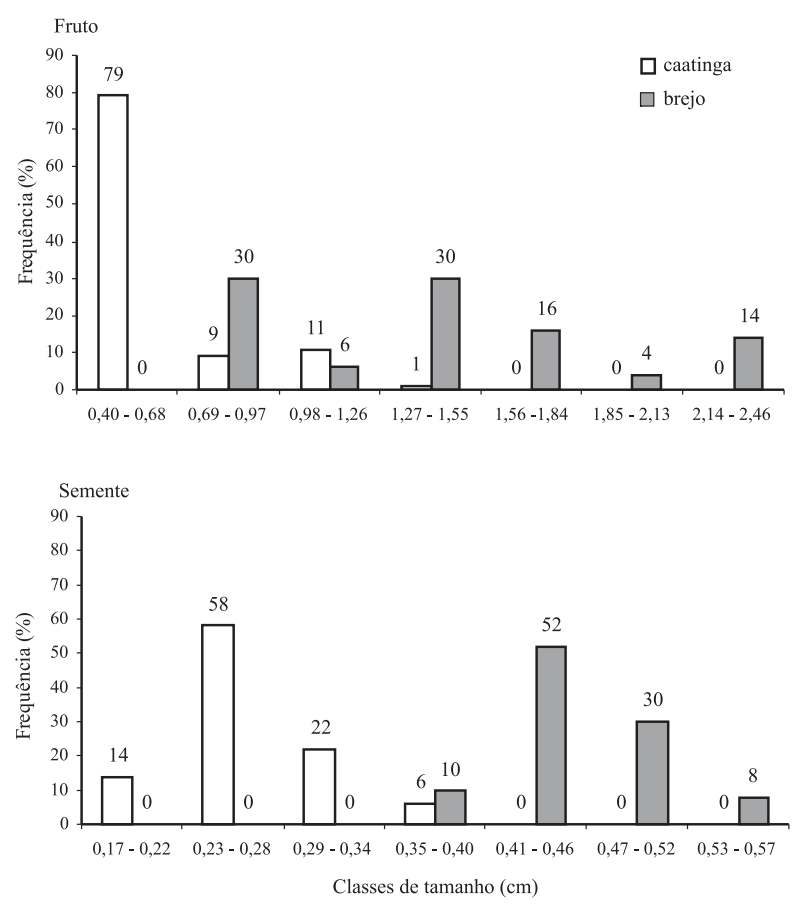

Figura 3 - Biomassa (g) de frutos e sementes de Erythrina velutina Willd. coletados em duas áreas (caatinga ebrejo de altitude), na região semiárida de Pernambuco. O número ao lado das barras representa o valor absoluto de frutos e sementes.

Figure 3-Biomass ( $g$ ) of fruits and seeds in Erythrina velutina Willd. collected in two areas (Caatinga and upper land swamp) in the semi-arid region of Pernambuco. The number next to the bar represents the absolute value of fruits and seeds. na qual foram registrados menores médias de precipitação (Figura 1) e solo menos rico em nutrientes, com relação ao brejo de altitude de Poção (Tabelas 1 e 2).

Quanto à biometria das sementes, observou-se que o comprimento, largura e espessura daquelas coletadas na área de caatinga variaram de 0,90 a $1,20 \mathrm{~cm}$, de 0,50 a $0,80 \mathrm{~cm}$ e de 0,50 a $0,70 \mathrm{~cm}$, respectivamente (Figura 4). Já nas sementes coletadas na área de brejo de altitude a variação foi de 1,10 a $1,50 \mathrm{~cm}$ no comprimento, de 0,70 a $1,10 \mathrm{~cm}$ na largura e de 0,60 a $0,90 \mathrm{~cm}$ na espessura. A amplitude de variação foi maior nas sementes do brejo de altitude. As classes mais representativas quanto ao comprimento, largura
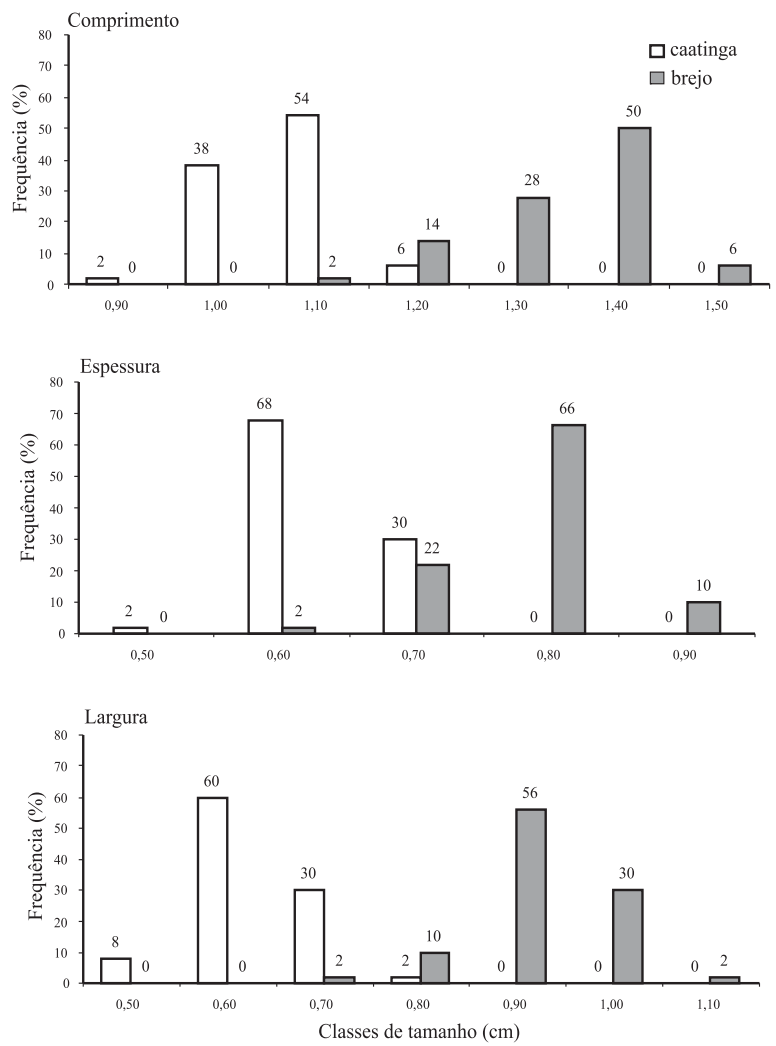

Figura 4-Comprimento, largura e espessura (cm) de sementes de Erythrina velutina Willd. coletadas em duas áreas (caatinga e brejo de altitude), na região semiárida de Pernambuco. O número ao lado das barras representa o valor absoluto de sementes.

Figure 4-Length, width and thickness (cm) of seeds in Erythrina velutina Willd. collected in two areas (Caatinga and upper land swamp) in semi-arid region of Pernambuco. The number next to the bar represents the absolute value of seed. 
e espessura nas áreas de caatinga e brejo de altitude foram assim distribuídas: comprimento $(1,10$ e 1,40 cm), largura $(0,60$ e $0,90 \mathrm{~cm})$ e espessura $(0,60$ e $0,80 \mathrm{~cm})$ (Figura 4). Portanto, as sementes de E. velutina coletadas na área de caatinga apresentaram valores médios para comprimento, largura e espessura menores que aqueles obtidos em área de brejo, assemelhando-se aos dados registrados dos frutos nas duas áreas (Tabela 3 ).

Sementes pequenas são mais eficientes na captura de água em relação às sementes grandes, devido à maior razão superfície/área (HARPER et al., 1970). Tal comportamento é vantajoso para espécies de caatinga, cuja disponibilidade de água se restringe praticamente durante a estação chuvosa, que dura cerca de três a quatro meses ao ano, favorecendo o processo de germinação (BARBOSA, 2003). Ainda segundo essa autora, no ecossistema caatinga sementes grandes ocorrem geralmente em espécies arbóreas, diminuindo em plantas arbustivas e herbáceas, as quais são mais predominantes.

A classificação das sementes em tamanho pode ser estratégia para aumentar a produtividade, visto que o tamanho da semente afeta a germinação, o vigor das plântulas e a produção de grãos (WHITE et al., 1992). Sementes grandes geralmente estão associadas na literatura às plântulas mais vigorosas ou possuidoras de maior massa fotossinteticamente ativa, favorecendo, em consequência, a sobrevivência delas em ambientes de baixa luminosidade (HARPER et al., 1970; FOSTER, 1986; FERREIRA; BORGHETTI, 2004). Variações no seu comprimento e largura podem implicar variações na forma da semente (ARAÚJO; NOGUEIRA, 2000). Apesar de haver, na literatura, tendência para relacionar o tamanho e forma da semente com o estágio sucessional das espécies, nem sempre é encontrada correlação significativa entre os estágios sucessionais com relação ao tamanho das sementes (SOUZA; VÁLIO, 2003). Vários fatores podem influenciar esse tamanho: posição da semente na inflorescência, estádio de diferenciação do embrião e reserva de alimento, que por sua vez podem influir na capacidade e vigor da germinação (LARCHER, 2000). Em condições particulares, a seleção pode favorecer a evolução de diásporos grandes em detrimento dos custos potenciais em reduzir a dispersão. A biometria mostra-se ferramenta auxiliar, sendo mais uma fonte de informação para os casos em que a classificação tradicional se mostre insuficiente ou gere classificação duvidosa (MORAES; ALVES, 2002). White et al. (1992) concluíram que sementes pequenas são fisiologicamente mais eficientes, especialmente as de locais quentes e altas latitudes.

A massa apresentou grande variação entre as sementes, verificando-se que na área de caatinga ocorreu uma variação de 0,17 a 0,36 g e na a área de brejo de altitude, de 0,35 a 0,59. Na caatinga, as classes mais representativas foram entre 0,23 e 0,28 g e no brejo de altitude, entre 0,41 a 0,46 g (Figura 3). A massa média de 100 sementes foi de 26,39 g na caatinga e de 45,69 g no brejo de altitude, o que permite inferir que $1 \mathrm{~kg}$ de sementes de E. velutina no brejo pode conter 2.188 e 3.787 sementes na caatinga. As sementes da caatinga são, em média, significativamente $(\mathrm{P}<0,05)$ mais leves que as do brejo de altitude. Segundo Malavasi e Malavasi (2001), o custo para a produção de sementes mais pesadas é aparentemente alto, levando em conta a diminuição na dispersibilidade e no seu crescimento relativo. Contudo, essa desvantagem aparente é contrabalançada pelo maior tamanho absoluto alcançado pelas mudas. Esses autores comentaram também que essa desvantagem seria ainda mais complexa pelo fato de que sementes pesadas possuem, em geral, tegumento mais espesso. Essa canalização de recurso para o tegumento pode refletir maior investimento na proteção contra predadores.

O volume das sementes mostrou uma visível separação entre as duas áreas analisadas: a amplitude das sementes coletadas na caatinga variou de 1,10 a $1,30 \mathrm{~cm}^{3}$ e as sementes coletadas no brejo de altitude, de 2,20 e $2,70 \mathrm{~cm}^{3}$, revelando uma das melhores medidas para diferenciar as duas populações. As sementes do brejo apresentaram significativamente $(\mathrm{P}<0,05)$ maiores volumes que as da caatinga. O valor médio de 100 sementes foi de $61,48 \mathrm{~cm}^{3}$ na caatinga e de $119,00 \mathrm{~cm}^{3}$ no brejo, o que permite inferir que $1 \mathrm{~cm}^{3}$ de sementes de $E$. velutina no brejo pode conter 1.626 e 840 sementes na caatinga. O volume das sementes pode ser considerado bom preditor de tamanho, uma vez que é mensurada apenas a área externa. Uma vez que sementes grandes apresentam maior superfície, com isso são maiores os problemas de balanço hídrico encontrados por elas, principalmente se ocorrerem em ambientes com altas temperaturas e baixa umidade superficial do solo (FOSTER, 1986).

Embebição - A embebição média das sementes escarificadas do brejo (162\%) foi superior à da caatinga (150\%), sendo ambas maiores que as intactas, indicando a resistência do tegumento à passagem da água (Tabela 4).

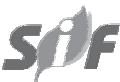

Revista Árvore, Viçosa-MG, v.36, n.2, p.247-257, 2012 
Esses resultados diferem daqueles encontrados por Morris et al. (2000) nas espécies Grevillea linearifolia (Corv.) Druce e Grevillea wilsonii A. Cunn., nas quais os tegumentos foram permeáveis à água, pois não foram encontradas diferenças na embebição entre as sementes intactas e escarificadas em ambas as espécies. A embebição das sementes coletadas, tanto na caatinga quanto no brejo de altitude, foi considerada rápida pela estabilização da curva de embebição após 8 h de observação (Figura 5). Resultados semelhantes foram encontrados nas espécies do Cerrado brasileiro Dalbergia miscolobium Benth. e Qualea cordata Spreng. (GODOY; FELIPPE, 1992; SASSAKI; FELIPPE, 1992).

Germinação - A germinação das sementes escarificadas de $E$. velutina obtiveram uma porcentagem média variando de 100 a 95\% no intervalo de seis dias, nas duas localidades analisadas sob luz contínua (Tabela 4). A germinação não foi registrada no período de experimento, entre as sementes de E. velutina intactas (controle). A velocidade de germinação foi superior nas sementes coletadas na caatinga $\left(0,254 \mathrm{~d}^{-1}\right)$ em relação às coletadas no brejo $\left(0,208 \mathrm{~d}^{-1}\right)$. Contudo, a escarificação mecânica aumentou a velocidade de germinação em ambas, demonstrando que esse tipo de escarificação é eficiente na superação da dormência tegumentar de E. velutina. Resultados semelhantes foram registrados em Acácia bonariensis Gill e Mimosa bimucronata

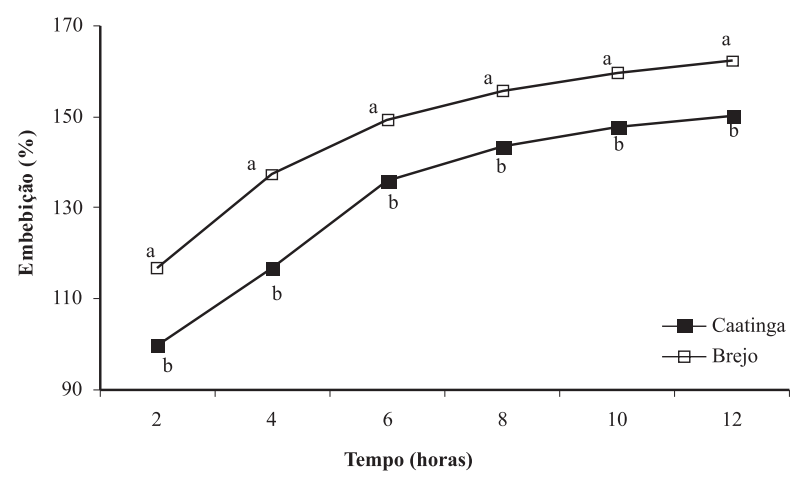

Figura 5-Embebição(\%) das sementes escarificadas de Erythrina velutina Willd. coletadas em duas áreas (caatinga e brejo de altitude) na região semiárida de Pernambuco. Letras iguais não diferem significativamente pelo teste $\mathrm{t}$ em amostras independentes $(\mathrm{P}>0,05)$.

Figure 5-Imbibition (\%) of scarified seeds of Erythrina velutina Willd. collected in two areas (Caatinga and upper land swamp) in the semi-arid region of Pernambuco. Equal letters do not differ significantly by the t test for independent samples $(P>0.05)$.
(DC.) O.K. (FERREIRA et al., 1992). Demonstrando, assim, que as sementes de E. velutina na natureza podem necessitar de escarificação para germinar, e a única barreira é de natureza física (tegumentar). A dormência nas sementes de leguminosas tropicais chega a atingir 98\% das sementes, sendo, portanto, um mecanismo comum dessa família (BEWLEY, BLACK, 1994; CRUZ et al., 2001). Fato demonstrado para as seguintes espécies de leguminosas: Samanea saman (Jacq.) Merr., Piptadenia moniliformis Benth., Caesalpinia ferrea Mart. ex. Tul., Mimosa caesalpinifolia (Benth.), Caesalpinia pyramidalis Tul., Adenanthera pavonina L., Canavalia dictyota Piper, Desmanthus virgatus (L.) Willd., Macroptilium bracteatum (Nees \& Mart.) Marechal. Mimosa lathyroides (L.) Urban, Tephrosia purpurea (L.) Pers. Sussp. e Purpurea e Prosopis caldenia Burk. (NASCIMENTO; OLIVEIRA, 1999; QUEIROZ, 1999; VILLALOBOS; PELÁEZ, 2001; ALVES et al., 2007; SOUZA et al., 2007).

O tegumento impermeável impede a passagem da água necessária para iniciar os processos de germinação, regulando a troca gasosa entre o embrião e o meio ambiente (SOUZA; MARCOS FILHO, 2001; SANTOS; CARDOSO, 2001), além de proteger o embrião contra injúrias mecânicas e ataques de pestes e doenças (SOUZA; MARCOS FILHO, 2001). É possível que o rompimento dessa camada se dê no solo, através da ação de microrganismos ou de abrasão, daí a germinação e o surgimento das plântulas, in loco, ocorrerem lentamente durante toda a estação chuvosa.

Neste estudo, a biometria dos frutos e das sementes, a embebição e a germinação de Erythrina velutina variaram entre os locais de coleta. Os frutos e as sementes da caatinga obtiveram os menores valores em todos os aspectos analisados, em comparação com os do brejo de altitude. As sementes do brejo apresentaram maior porcentagem de embebição, entretanto menor velocidade de germinação. Esses dados indicaram que a área da caatinga analisada (Alagoinha) propiciou para as plantas parentais de E. velutina condições menos favoráveis de suprimento hídrico e nutrientes no solo. Isso permitiu a reprodução da espécie (produção de frutos e sementes), bem como a germinação, comparando a área de brejo de altitude (Poção), na região semiárida do Estado de Pernambuco. Entretanto, a produção de frutos e sementes menores pelas plantas da caatinga é estratégia que otimiza a utilização de menor recurso hídrico disponível. 


\section{REFERÊNCIAS}

ALVES, E. U. et al. Superação de dormência em sementes de Caesalpinia pyramidalis Tul. Revista Arvore, v.31, n.3, p.405-415, 2007.

ANDRADE LIMA, D. Esboço fitoecológico de alguns "Brejos” de Pernambuco. Separata do Boletim Técnico do Instituto de Pesquisas Agronômicas de Pernambuco, v.8, p.3-10, 1966.

ARAÚJO, E. L.; NOGUEIRA, R. J. M. C. Tamanho de sementes e viabilidade de embriões em mangabeira (Hancornia speciosa Gomes). Naturalia, v.25, p.139-148, 2000.

AYRES, M. et al. Bioestat 2.0: Aplicações estatísticas nas áreas das ciências biológicas e médicas. Belém: Sociedade Civil Mamirauá; Brasília: CNPq, 1998.

BARBOSA, D. C. A. Estratégias de germinação e crescimento de espécies lenhosas da caatinga com germinação rápida. In: LEAL, I. R.; TABARELLI, M.; SILVA, J. M. (Eds.). Ecologia e conservação da caatinga. Recife: Universitária UFPE, 2003. p.625-656.

BEWLEY, J. D.; BLACK, M. Seed: physiology of development and germination. New York: Plenum, 1994. 460p.

BORGES, E. E. L.; RENA, A. B. Germinação de sementes. In: AGUIAR I. B.; PIÑA-RODRIGUES F. C. M.; FIGLIOLIA M. B. (Eds.). Sementes florestais tropicais. Brasília: ABRATES, 1993. p.83-135.

BRASIL. Ministério da Agricultura e Reforma Agrária. Departamento Nacional de Defesa Vegetal CLV. Regras para Análise de Sementes, Brasília: 1992. 365p.

COUVILLON, G. A. Cercis canadensis L. seed size influences germination rate, seedling dry matter, and seedling leaf area. Hortscience, v.37, n.1, p.206-207, 2002.

CRUZ, E. D. et al. Biometria de frutos e sementes e germinação de jatobá-curubá (Hymenaea intermédia Ducke, Leguminosae Caesalpinioideae). Revista Brasileira de Biologia, v.24, n.2, p.161-165, 2001.
FERRAZ, E. M. N. et al. Composição florística em trechos de vegetação de caatinga e brejo de altitude na região do vale do Pajeú, Pernambuco. Revista Brasileira de Botânica, v.21, n.1, p.7-15, 1998.

FERREIRA, A. G.; BORGHETTI, F.

Germinação: do básico ao aplicado. Porto Alegre: Artmed, 2004. 321p.

FERREIRA, A. G. et al. Efeitos de escarificação sobre a germinação e do $\mathrm{pH}$ no crescimento de Acácia boraniensis Gill e Mimosa bimucronata (D.C.) O.K. Revista Brasileira de Fisiologia Vegetal, v.4, n.1, p.63-65, 1992.

FIAM - Fundação de desenvolvimento municipal do interior de Pernambuco. Perfil Municipal do Interior de Pernambuco, Recife: 1996.

FOSTER, S. A. On the adaptative value of large seeds for tropical moist forest trees: a review and synthesis. The Botanical Review, v.52, n.3, p.260-295, 1986.

GODOY, S. M. A.; FELIPPE, G. M. Crescimento inicial de Qualea cordata, uma árvore dos cerrados. Revista Brasileira de Botânica, v.15, n.1, p.23-30, 1992.

HARPER, J. L. et al. The shapes and sizes of seeds. Annual Review of Ecology and Systematics, v.1, p.327-356, 1970.

JACOMINE, P. K. T. et al. Levantamento exploratório-reconhecimento de solos do Estado de Pernambuco. Recife: 1973. v.1. 359p. (Boletim Técnico, 26/Série Pedologia, 14).

KHAN, M. L. et al. Seed germination and seedling fitness in Mesua ferrea L. in relation to fruit size and seed number per fruit. Acta Oecologica, v.20, n.6, p.599-606, 1999.

LABOURiAu, L. G. A germinação das sementes. Washington: Secretaria - Geral da Organização dos Estados Americanos, 1983. (Série Biologia, Monografia, 24)

LAMEP/ITEP - Instituto de Tecnologia de Pernambuco. Recife: 1996.

LARCHER, W. Ecofisiologia vegetal. São Carlos: Rima Artes e Textos, 2000. 531p.

Revista Árvore, Viçosa-MG, v.36, n.2, p.247-257, 2012 
LORD, J. M.; MARSHALL, J. Correlations between growth form, habitat, and fruit colour in the New Zealand flora, with reference to frugivory by lizards. New Zealand Journal of Botany, v.39, n.4, p.567-576, 2001.

MALAVASI, U. C.; MALAVASI, M. M. Influência do tamanho e do peso da semente na germinação e no estabelecimento de espécies de diferentes estágios da sucessão vegetal. Floresta e Ambiente, v.8, n.1, p.211-215, 2001.

MAYER, A. M.; POLJAKOFF-MAYBER, A. The germination of seed. Oxford, Pregamon Press, 1979. 270p.

MORAES, P. L. R.; ALVES, M. C. Biometria de frutos e diásporos de Cryptocarya aschersoniana Mez e Cryptocarya moschata Nees (Lauraceae). Biota Neotropica, v.2, n.1, p.1-11, 2002.

MORRIS, E. C. et al. Seed coat dormancy in two species of Grevillea (Proteaceae). Annals of Botany, v.86, p.771-775, 2000.

NASCIMENTO, M. P. S. C. B.; OLIVEIRA, M. E. A. Quebra de dormência de sementes de quatro leguminosas arbóreas. Acta Botanica Brasílica, v.13, n.2, p.129-137, 1999.

POPINIGIS, F. Fisiologia da semente. Ministério da Agricultura - AGIPLAN. 1985.

QUEIROZ, L. P. Leguminosas de caatinga, espécies com potencial forrageiro. In: ARAÚJO F. D.; PRENDERGAST, H. D. V.; MAYO, S. J. (Eds.). Plantas do Nordeste. WORKSHOP GERAL. ROYAL BOATNIC GARDENS, 1., 1999, Kew. Anais... Kew: 1999. p.63-65.

RODAL, M. J. N. et al. Fitossociologia do componente lenhoso de um refúgio vegetacional no município de Buíque, Pernambuco. Revista Brasileira de Biologia, v.58, n.3, p.517-526, 1998.

SALES, M. F.; et al. Plantas vasculares das florestas Serranas de Pernambuco. Recife: Universidade Federal Rural de Pernambuco, 1998. 130p.

SANTOS, D. L.; CARDOSO, V. J. M. Thermalbiological aspects on the seed germination of Cucumis anguria L.: influence of the seed coat. Revista Brasileira de Botânica, v.24, n.4, p.435-440, 2001.

Revista Árvore, Viçosa-MG, v.36, n.2, p.247-257, 2012
SASSAKI, R. M.; FELIPPE, G. M. Remoção dos cotilédones e desenvolvimento inicial de Dalbergia miscolobium. Revista Brasileira de Botânica, v.15, n.1, p.5-16, 1992.

SASSAKI, R. M.; FELIPPE, G. M. Singleseeded fruits and seedling estabilishment in Dalbergia miscolobium Benth.

(Papilionaceae). Biotropica, v.31, n.4, p.591-597, 1999.

SOUZA, E. B. et al. Germinação de sementes de Adenanthera pavonina L. em função de diferentes temperaturas e substratos. Revista Árvore, v.31, n.3, p.437-443, 2007.

SOUZA, F. H. D.; MARCOS FILHO, J. The seed coat as a modulator seed-environment relatioship in Fabaceae. Revista Brasileira de Botânica, v.24, n.4, p.365-375, 2001.

SOUZA, R. P.; VÁLIO, I. F. M. Seedling growth of fifteen tropical tree species deffering in sucessional status. Revista Brasileira de Botânica, v.26, n.1, p.35-47, 2003.

TABARELLI, M.; SANTOS, A. M. L. Uma breve descrição sobre a história natural dos brejos nordestinos. In: PÔRTO, K. C.; CABRAL, J. J. P.; TABARELLI, M. (Orgs.). Brejos de altitude em Pernambuco e Paraíba: história natural, ecologia e conservação. Brasília, Ministério do Meio Ambiente, 2004. p.17-24. (Série Biodiversidade, 9)

TABARELLI, M. et al. Variation of seed dispersal spectrum of woody plants across a rainfall gradient in north-eastern Brazil. Journal of Arid Environments, v.53, p.197-210, 2003.

THOMPSON, K. et al. Seed size, shape and persistence in the soil in an Iranian flora. Seed Science Research, v.11, n.4, p.345-355, 2001.

VASCONCELO SOBRINHO, J. As regiões naturais do nordeste, o meio e a civilização. Recife, Conselho de Desenvolvimento de Pernambuco, 1970. 442p.

VILLALOBOS, A. E.; PELÁEZ, D. V. Influences of temperature and water stress on germination and establishment of Prosopis caldenia Burk. Journal of Arid Environments, v.49, p.321-328, 2001. 
WACHOWICZ, C. M.; CARVALHO, R. I. N. Fisiologia vegetal: produção e pós-colheita. Curitiba: Champagnat, 2002. 423p.

WHiTE, J. W.; GONZÁLEZ, A.

Characterization of the negative association between seed yield and seed size among genotypes of common bean. Field Crops Research, v.23, p.159-175, 1990.
WHITE, J. W. et al. Effects of seed size and photoperiod response on crop growth and yield of common bean. Field Crop Research, v.28, p.295-307, 1992.

WILLSON, M. F. et al. Vertebrate dispersal syndrome in some Australian and New Zealand plant communities, with geographic comparisons. Biotropica, v.21, p.133-147, 1989. 
